\title{
FRICTION REDUCTION BY ADDING COPPER OXIDE INTO ALUMINA AND ZIRCONIA CERAMICS
}

\author{
H.R. Pasaribu \\ Surface Technology and Tribology Section, Faculty of Engineering Technology, University of Twente \\ Drienerloolaan 5, Postbus 217, 7500 AE, Enschede, The Netherlands
}

The friction and wear of alumina and zirconia ceramics doped with various weight percentages $(0.5 \%$ wt, $1 \%$ wt and $5 \%$ wt) of CuO was studied. Dry sliding tests by using a pin-on-disc tribotester were conducted on these materials against commercially available Al2O3, ZrO2, SiC, and Si3N4 ceramic balls.

The results show that $\mathrm{CuO}$ give a significant reduction of friction only when the alumina and zirconia doped with $\mathrm{CuO}$ were sliding against $\mathrm{Al} 2 \mathrm{O} 3$ balls. The coefficient of friction of $\mathrm{CuO}$ doped in alumina sliding against $\mathrm{Al} 2 \mathrm{O} 3$ balls reduces from 0.7 to 0.4 and hardly depends on the normal load and the velocity. On the other hand, $\mathrm{CuO}$ doped in zirconia can reduce the coefficient of friction (when sliding against $\mathrm{Al} 2 \mathrm{O} 3$ balls) from 0.8 to a value of about 0.2 and 0.3 depending on the normal load.

SEM pictures taken from the wear track showed that smooth patchy layers were formed. These smooth patchy layers, which carry the normal load, are responsible in reducing the coefficient of friction.

Keywords: Ceramics, CuO, low friction 